\title{
Correlation of Malondialdehyde (MDA) and C-reactive Protein (CRP) Level to Neurodevelopmental Outcome in Children After the Episode of Convulsive Type Status Epilepticus
}

\author{
Sintha Restuningwiyani ${ }^{1 *}$, Ariani ${ }^{1}$, Hidayat Sujuti ${ }^{2}$, Masruroh Rahayu ${ }^{3}$, Krisni Subandiyah ${ }^{1}$ \\ ${ }^{1}$ Department of Pediatrics, Faculty of Medicine, Brawijaya University, Malang 65145, Indonesia \\ 2 Department of Biochemistry, Faculty of Medicine, Brawijaya University, Malang 65145, Indonesia \\ ${ }^{3}$ Department of Neurology, Faculty of Medicine, Brawijaya University, Malang 65145, Indonesia
}

\author{
Article history: \\ Submission December 2017 \\ Revised January 2018 \\ Accepted April 2018 \\ *Corresponding author: \\ E-mail: \\ sintharestuningwiyani \\ @gmail.com
}

\begin{abstract}
Refractory and mortality associated with status epilepticus (SE) were correlated with the degree of inflammation-induced neuronal cell death. This study was aimed to investigate the correlation of oxidative stress (Malondialdehyde, MDA) and inflammation (C-reactive protein, CRP) process with neurodevelopmental outcome in children after the episode of convulsive type SE. This study was designed as cross sectional which included 26 convulsive type SE subjects and 15 control subjects. MDA level was measured by thiobarbituric acid (TBA) method, while CRP level was measured by ELISA method. Neurodevelopmental outcome was measured by Bayley-III Scale of Infant and Toddler Development 3 month after the convulsive type SE episode. Results showed that both MDA (independent t-test, $\mathrm{p}<0.05$ ) and CRP (Mann-Whitney test, $\mathrm{p}<0.05$ ) level was significantly higher in convulsive type SE group as compared to control group. Further analysis also showed that MDA (Spearman correlation test, $\mathrm{p}=0.000, \mathrm{r}=0.756$ ) and CRP (Spearman correlation test, $\mathrm{p}=0.000, r=0.835$ ) level was positively correlated with convulsive type SE. In convulsive type SE group, MDA level was negatively correlated with neurodevelopmental outcome but CRP was not. We concluded that MDA level was negatively correlated with neurodevelopmental outcome in children with convulsive type SE, but CRP was not.
\end{abstract}

Keywords: C-reactive protein, malondialdehyde, neurodevelopmental outcome, status epilepticus

\section{Introduction}

Status epilepticus (SE) is defined as prolonged seizure which occurred for 20-30 minutes or repeated seizure in which patients is unconscious between two episodes of seizures [1, 2]. Convulsive $\mathrm{SE}$ is a generalized SE with tonic-clonic, tonic, clonic, and myoclonic movement. The incidence of SE in children aged 1-19 years old was approximately $10-58$ cases/100.000/ year [1, 2]. In children below 1 year old, the incidence of SE was higher (135.2 - 156 cases/100.000/ year [1, 2].

As reported before, repeated seizure could lead to neurodevelopmental impairment such as cognitive dysfunction and behavior and emotional disturbances [3,4]. Similarly, children with refractory SE could lead to the visual and motoric deficit after the onset of SE [5]. A retrospective study showed that several neurological abnormalities were found in children after the episode of SE such as impairment of speech, coordination and behavior, hemiplegia, and epilepsy [6]. Many factors were considered to triggered neurodevelopmental outcome in SE such as aged less than 12 years old and focal onset seizure [7].

In a seizure, the inflammatory condition could lead to the formation of reactive oxygen species (ROS) and lipid peroxidation which in turn lead to neuronal apoptosis and necrosis [8]. Malondialde-

\section{How to cite:}

Restuningwiyani S, Ariani, Suyuti H et al. (2018) Correlation of Malondialdehyde (MDA) and C Reactive Protein (CRP) Level to Neurodevelopmental Outcome in Children After the Episode of Convulsive Type Status Epilepticus. Journal of Tropical Life Science 8 (3): 251 - 258. doi: 10.11594/jtls.08.03.07 
hyde (MDA) as the end product of lipid peroxidation could cause DNA damage and sequentially activate neuronal apoptotic pathway [9, 10]. MDA binds and cross-reacts with various biological macromolecules such as protein and nucleid acid and altered its functionality then impaired neurodevelopmental process [11].

C-reactive protein (CRP) is acute phase protein that secreted by hepatic tissue and widely used as inflammation or infection marker [12]. In SE, CRP could be used as a predictor for refractory and prognostic marker. CRP was elevated in pilocarpine-induced SE rat model [13]. Furthermore, CRP also elevated in patient with refractory SE and its level was correlated with mortality [14].

This study was aimed to investigate the correlation of MDA and CRP level with neurodevelopmental outcome after the episode of convulsive type SE in children.

\section{Material and Methods Study design}

This study was designed as a cross sectional to evaluate the neurodevelopmental outcome of children aged 1-42 months old after convulsive type SE episode (3 months follow up period). Furthermore, this study was aimed to correlate the MDA and CRP level in the first day of convulsive type seizure episode with neurodevelopmental outcome. This study was conducted at Pediatric Ward, Emergency Room, and pediatric outpatient care of Saiful Anwar Hospital, Malang, Indonesia; Physiology Laboratory of Medical Faculty of Brawijaya University. All of the procedure had been approved by Ethical Committee of Research Saiful Anwar Hospital issued by Ethical Clearance number 400/18/K.3/302/2016.

\section{Subject and population}

Inclusion criteria for the sample are as follows: aged 1 - 42 months with convulsive type SE, normal developmental status before convulsive type SE episode, and allowed by his/her parents to join this study. Inclusion criteria for control are as follows: a pediatric patient who attended pediatric outpatient care without seizure, normal developmental status and allowed by his/her parents to join this study (represented by signed informed consent form). Exclusion for sample and control are as follows: children with major congenital diseases, history of trauma or intracranial procedure which associated with impaired developmental status, and severe sepsis. Drop out criteria for all subjects are as follows: lysis of blood sampling, died or underwent the intracranial procedure during the study, intracranial structural abnormality after the episode of convulsive type SE, and didn't come at follow up period.

\section{Sample size calculation}

The formula to calculate the sample size for this study was:

$$
\mathrm{N}=\frac{Z^{2} S D^{2}}{d^{2}}
$$

Note:

$\mathrm{Z} \quad=$ standard normal variate (at $5 \%$ type 1 error ( $<<$ 0.05 ) it is 1.96)

$\mathrm{SD}=$ standard deviation of variable.

$\mathrm{d} \quad=$ absolute error or precision

Based on pilot study, SD of CRP level was 0.25 and the $d$ value was $15 \%$, so the sample size derived from the formula was 10.67 . Hence, 15 subjects were recruited in this study.

\section{Blood sampling}

Subjects who met inclusion criteria was undergone to take his/her blood at the first day of convulsive type SE episode. Venous blood sample was transferred to the laboratory using tube until it coagulated (2 hours at room temperature, overnight at $4^{\circ} \mathrm{C}$ ). After this, the sample was centrifuged for 20 minutes at $1000 \mathrm{rpm}$. Plasma which separated after centrifugation process was immediately examined for MDA and CRP measurement or stored at $-40^{\circ} \mathrm{C}$ or $-80^{\circ} \mathrm{C}$.

\section{Measurements of MDA}

Thiobarbituric acid (TBA) was made by mixing of $0.67 \mathrm{~g}$ TBA in $100 \mathrm{~mL}$ aquabidest, then added by 0.5 gsodium hydroxide and $100 \mathrm{~mL}$ glacial acetic acid. Serial standard solution and stock solution (MDA $125 \mathrm{uL}$ in $100 \mathrm{~mL}$ aquabidest) were prepared. As many $100 \mathrm{uL}$ plasma sample and standard were transferred into each tube. Each tube was added with $0.9 \mathrm{~mL}$ aquabidest and 0.5 $\mathrm{mL}$ reagent TBA. A mixture of sample/ standard together with TBA reagent was heated using water bath at $95^{\circ} \mathrm{C}$ for 1 hour. After this process, each tube was centrifuged at 7,000 rpm for 10 minutes. Supernatant was taken from each tube and analy- 
zed for its absorbance value using spectrophotometer (wavelength $532 \mathrm{~nm}$ ).

\section{Measurement of CRP}

CRP level was examined by ELISA method. ELISA procedure was performed as instructed by manufacturer (Human C-Reactive Protein Quantikine ELISA Kit, RnD systems, catalogue number DCRP00). Briefly, plasma sample which had been obtained from the previous procedure was thawed at room temperature. All ELISA reagents include standard solution, assay diluent $\mathrm{A}$ and $\mathrm{B}$, detection reagent $A$ and $B$, washing solution, and TMB substrate were prepared. $100 \mathrm{uL}$ assay diluent RD1F was added into each well. $50 \mathrm{uL}$ standard, control, or sample were added to each well and closed with an adhesive strip, then incubated for 2 hours at $37^{\circ} \mathrm{C}$. After incubation process, each well was aspirated and added to $400 \mathrm{uL}$ washing solution. This washing process was repeated for 3 times. After washing process, $200 \mathrm{uL}$ CRP conjugate was added to each well, closed with an adhesive strip, and then incubated for 2 hours at room temperature. Washing process was repeated as described before. $200 \mathrm{uL}$ substrate solution was added to each well then incubated for 30 minutes at room temperature in the dark room. $50 \mathrm{uL}$ stop solution was added to each well. Microplate then analyzed for its absorbance value using ELISA reader at wavelength $450 \mathrm{~nm}$ after 30 minutes. CRP level was determined by plotting each sample's absorbance value into a standard curve.

\section{Assessment of neurodevelopmental outcome}

Basically, the neurodevelopmental outcome was measured by Bayley-III Scale of Infant and Toddler Development. This scale was divided into 3 main scores: motoric, language, and cognitive score $[16,17]$.

\section{Statistical analysis}

First, data of MDA, CRP level and neurodevelopmental were analyzed for their distribution and homogeneity. In order to analyze the differences of MDA, CRP level and neurodevelopmental outcome between groups, independent t-test (Mann-Whitney test as an alternative) was performed. Correlation of status epilepticus and MDA and CRP level, status epilepticus and neuro developmental outcome; CRP and MDA level and neurodevelopmental outcome were analyzed us- ing Pearson correlation test (Spearman correlation test as an alternative). All the statistical analyses were performed using software SPSS version 23.0.

\section{Results and Discussion \\ Baseline characteristics}

This study was included children with convulsive type status epilepticus which hospitalized in Saiful Anwar General Hospital Malang. As many as 41 subjects were included in this study which divided into 26 subjects as convulsive type status epilepticus group and 15 subjects in the control group. Baseline characteristics of convulsive type status epilepticus group were shown in Table 1.

This study observed neurodevelopmental outcome (cognitive, language, and motoric based on Bayley III) in children diagnosed with convulsive type status epilepticus 3 months after convulsive type seizure episode. Of 40 subjects with convulsive type status epilepticus, only 26 subjects were

Table 1. Characteristics of subjects

\begin{tabular}{ll}
\hline \multicolumn{1}{c}{ Characteristics } & Number (n) \\
\hline Sex & \\
- Male & 15 \\
- Female & 11 \\
\hline Age (months) & \\
$-0-6$ & 5 \\
$-7-12$ & 6 \\
$-13-24$ & 10 \\
$->24$ & 5
\end{tabular}

Nutritional Status

- Over-Nutrition 1

- Good 9

- Undernutrition 13

- Malnourished 3

Mother's Educational Background

- Senior High School and above level 17

- Junior High School and below level 9

Hemoglobin Level (g/dL)

$\begin{array}{lll}-<11.0 & 13\end{array}$

- > $11.0 \quad 13$

Leukocyte Count (cells $/ \mathrm{mm}^{3}$ )

$\begin{array}{ll}-<10,000 & 10\end{array}$

$-10,000-15,000$

- > 15,000 11 


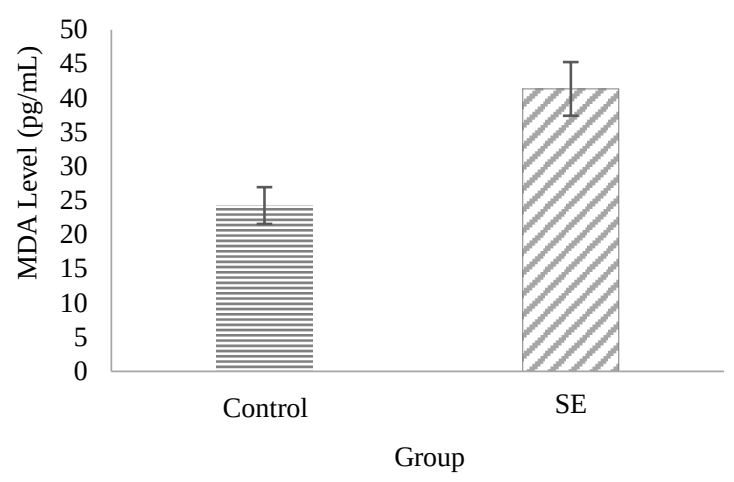

Figure 1. Mean of MDA level (pg/mL) in control and convulsive type SE group

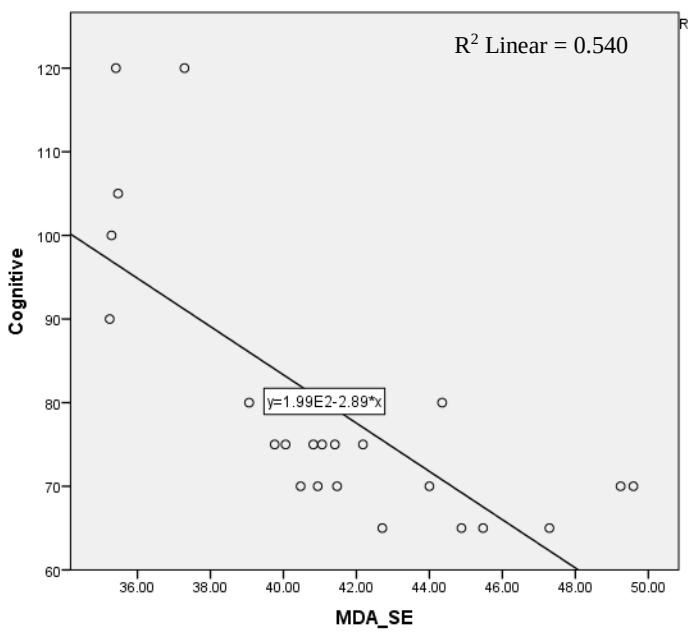

Figure 2. Correlation graph of MDA level and cognitive composite in convulsive type SE group

analyzed. As many as 14 subjects were dropped out caused by died (4 subjects), underwent an intracranial procedure or severe disease (5 subjects), and did not come at follow-up period (5 subjects). Characteristic of subjects in convulsive type status epilepticus group showed that male was more than the female subject (15 of 26 subjects). The most age interval was 13 - 24 months old in convulsive type SE group. Interestingly, nutritional status of subjects in convulsive type SE group was mainly undernutrition and malnourished, indicating that poor nutrition status increases the vulnerability to severe infection. Educational background of the mother seems did not contribute to the development of status epilepticus. However, this aspect needs further investigation.

Hemoglobin level might do not significantly increase the risk of convulsive type status epilepticus. However, it needs further research about the role of hemoglobin level in the progression of disease. Leukocyte count in convulsive type status epilepticus group showed that almost patient had leukocyte count above 10,000 cells $/ \mathrm{mm}^{3}$ and 5 among those group had leukocyte count above 15,000 cells $/ \mathrm{mm}^{3}$, suggesting that severe inflammation such as complex febrile seizure or meningoencephalitis could be associated with status epilepticus. Normal leukocyte condition which could contribute to triggering status epilepticus such as uncontrolled epilepsy (poor patient's obedience to take drug) and electrolyte imbalance (severe vomiting and diarrhea).

\section{MDA level}

Result showed that MDA level in convulsive type SE group (41.35 $\pm 3.93 \mathrm{pg} / \mathrm{mL})$ was significantly higher as compared to control group (24.28 $\pm 2.69 \mathrm{pg} / \mathrm{mL}$ ) (independent t-test, $\mathrm{p}<0.05$ ). The mean of MDA level in both convulsive type SE and control group was shown in Figure 1. Furthermore, Spearman correlation test showed that convulsive type status epilepticus was positively corelated with MDA level $(p=0.000, r=0.756)$. Malondialdehyde is a marker for lipid peroxidation and known as the most mutagenic lipid peroxidation end product. Oxidative stress which leads to reactive oxygen species (ROS) formation was associated with the pathological finding in acute seizure, status epilepticus, and epilepsy. Evidence showed that ROS was elevated in in vivo model of epilepsy marked by reduced glutathione level [17, 18]. Reactive oxygen species could impair cell integrity mediated by MDA formation [19].

An experimental study using rat SE model (pilocarpine-induced) demonstrated that MDA level was elevated in prolonged seizure group as compared to repeated group [20]. Further analysis showed that neuronal cell death and single strand DNA was elevated in prolonged seizure group as compared to repeated seizure [20].

Similarly, other experimental study using pilocarpine-induced rat SE model also showed that hippocampal oxidative stress marked by lipid peroxidation and nitrite content was elevated in SE group as compared to control group [21]. Using the same model, Junior and colleagues also demonstrated that lipid peroxidation in striatum area (47\%) and frontal cortex (59\%) were elevated [22]. Previous studies suggested that oxidative stress which triggered lipid peroxidation might 


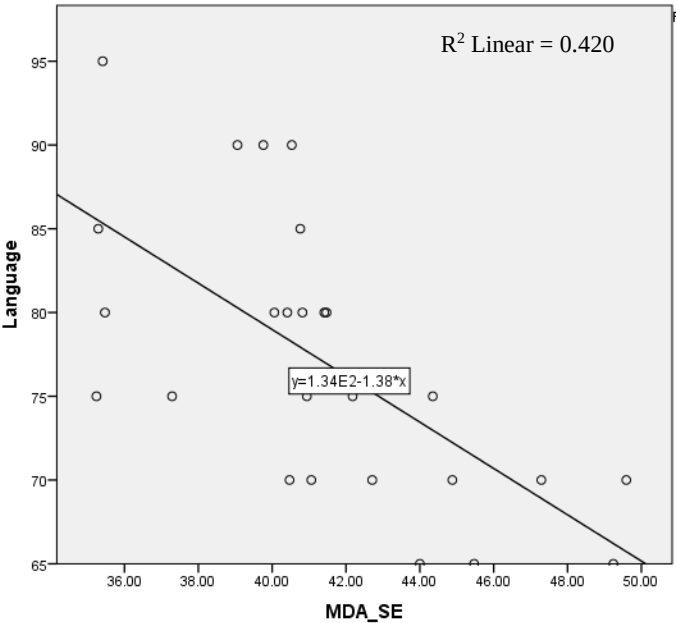

Figure 3. Correlation graph of MDA level and language composite in convulsive type $\mathrm{SE}$ group

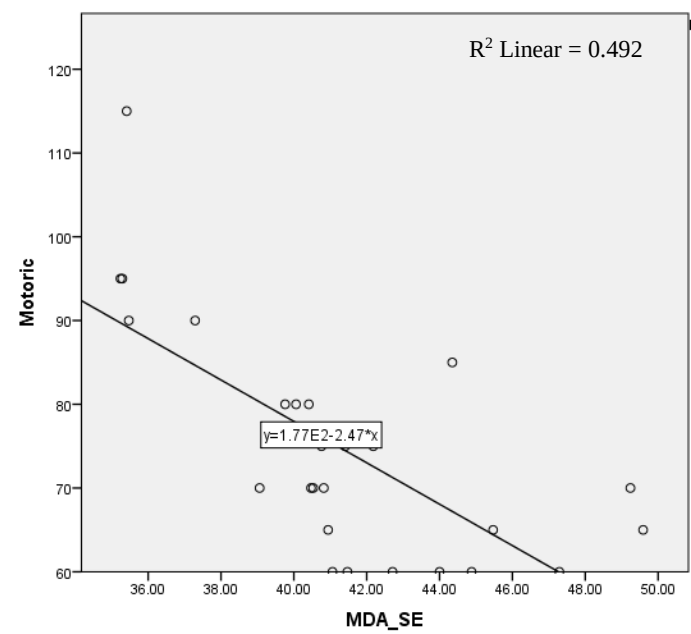

Figure 4. Correlation graph of MDA level and motoric composite in convulsive type SE group

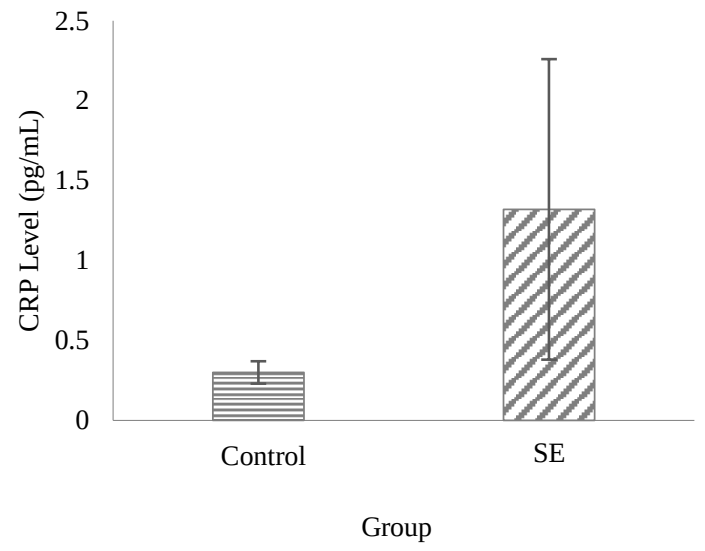

Figure 5. Mean of CRP level (pg/mL) in control and convulsive type SE group have crucial role in SE.

\section{Correlation of MDA level and neurodevelopmen- tal outcome}

Correlation study of MDA level and neurodevelopmental outcome demonstrated that MDA level was negatively correlated with cognitive composite (Spearman correlation test, $\mathrm{p}=0.000, \mathrm{r}$ $=-0.800$ ). Similarly, MDA level was negatively correlated with language composite (Pearson correlation test, $\mathrm{p}=0.000, \mathrm{r}=-0.648$ ). Further analysis also showed that MDA level was negatively correlated with motoric composite (Spearman correlation test, $\mathrm{p}=0.000, \mathrm{r}=-0.732$ ). Overall, correlation study confirmed that MDA level was negatively correlated with neurodevelopmental outcome in convulsive type status epilepticus children based on cognitive, language, and motoric aspect. Correlation graph of MDA level and cognitive composite, language composite, and motoric composite was shown in Figure 2, Figure 3, and Figure 4, respectively. These results suggested that MDA has an important role in the occurrence of neuron hyper-excitability and inflammation-induced neuronal injury which lead to refractory seizure and post-seizure neurodevelopmental dysfunction.

Several studies had been conducted to investigate neurodevelopmental outcome in SE. Saz and colleagues reported that children with refractory SE might experience visual and motoric deficit after the onset of seizure [23]. Another observational study also reported that $18 \%$ children with SE experience neurological sequelae at the day they discharged from hospital and further analysis showed that hypoglycemia, aged less than 12 years old, and focal onset seizure increase those Sequleae's occurrence [7]. The retrospective study also demonstrated that 9 children with SE experience impairment of speech, coordination and behavior, hemiplegia, and epilepsy development after the onset of the seizure [6]. Repeated seizure post encephalitis also insignificantly increases the risk of epilepsy (OR 2.4) [24].

MDA could bind and cross-react with various macromolecules such as protein and nucleic acid which played an important role in neuronal development [11]. In vivo study also showed that MDA could cause an imbalance of glutamate and GABA (gamma amino butyric acid) activity and induce neuronal apoptotic pathway [9]. 
Oxidative stress was not only involved MDA, but also other ROS which formed at hypermetabolic state (seizure) and mediated by activation of NADPH oxidase and xanthine oxidase [25]. Oxidative stress considered as an important factor for the development of brain pathological condition in seizure (acute seizure, status epilepticus, and epilepsy) [26]. Oxidative stress had a contribution to the development of neuronal cell death [18], and several studies showed that MDA increases the risk of chronic epilepsy development $[19,27]$. The source of cellular oxygen free radical were mitochondria [28], NADPH activation [29], xanthine oxidase action [30] and those free radicals involved in the development of pathological condition such as epilepsy and stroke.

\section{CRP level}

Result showed that CRP level in convulsive type SE group $(1.32 \pm 0.94 \mathrm{pg} / \mathrm{mL})$ was significantly higher as compared to control group ( $0.3 \pm$ $0.07 \mathrm{pg} / \mathrm{mL}$ ) (Mann-Whitney test, $\mathrm{p}<0.05$ ). The mean of CRP level in both convulsive type SE and control group was shown in Figure 5. Furthermore, Spearman correlation test showed that convulsive type status epilepticus was positively correlated with CRP level $(\mathrm{p}=0.000, \mathrm{r}=0.835)$.

\section{Correlation of CRP level and neurodevelopmen- tal outcome}

Correlation study of CRP level and neurodevelopmental outcome demonstrated that CRP level was insignificantly correlated with cognitive composite (Spearman correlation test, $\mathrm{p}=0.640, \mathrm{r}$ $=-0.096$ ). Similarly, CRP level was insignificantly correlated with language composite (Spearman correlation test, $\mathrm{p}=0.549, \mathrm{r}=-0.123$ ). Further analysis also showed that CRP level was insignificantly correlated with motoric composite (Spearman correlation test, $\mathrm{p}=0.944, \mathrm{r}=0.015$ ). Overall, correlation study confirmed that CRP level was insignificantly correlated with neurodevelopmental outcome in convulsive type status epilepticus children based on cognitive, language and motoric aspect.

C-reactive protein is acute phase protein which secreted by hepatic tissue as a response to inflammation include meningoencephalitis. CRP level was also increased in epilepsy and this fact suggested that systemic inflammation was associated with general seizure in epilepsy [31, 32]. In
SE, CRP was used a predictor for refractory SE and predictor for prognostic SE patient. Observational study included 160 patients from ICU demonstrated that CRP and procalcitonin could be used as a predictor for infection in SE patient (sensitivity $83 \%$ and $94 \%$, respectively; negative predictive value increase for 3 days for 97\%) [14]. CRP also used as an outcome predictor in SE patient. Cohort study revealed that elevated CRP level was associated with refractory SE and mortality [32].

Consistent with the previous study, an experimental study using pilocarpine-induced model also showed that CRP was increased in SE group as compared to control [13]. Retrospective cohort study further showed that the outcome of children with SE was associated with age $<24$ months, seizure duration $>90$ minutes, abnormal blood glucose level ( $<61$ or $>250 \mathrm{mg} / \mathrm{dL}$ ), AST level $>56$ $\mathrm{UI} / \mathrm{L}$, and CRP level $>2.00 \mathrm{mg} / \mathrm{dL}$ (univariate analysis) [32]. Multivariate analysis further confirmed that young age, abnormal blood glucose level, elevated AST and CRP level was significantly correlated with poor prognosis [32]. However, our study did not show any correlation between CRP level and neurodevelopmental outcome in convulsive type status epilepticus children and this might be caused by timing and location of blood sampling which did not represent the peak of inflammation and cerebral inflammation.

\section{Conclusion}

We concluded that MDA level was negatively correlated with neurodevelopmental outcome in children after the episode of convulsive type status epilepticus, but CRP was not.

\section{Acknowledgment}

The authors wish to thank the Department of Pediatrics, Saiful Anwar Hospital, Faculty of Medicine, Brawijaya University for the support througout research period. We also thank to Biomedical Laboratory, Faculty of Medicine, Brawijaya University for the assistance of laboratory analysis.

\section{References}

1. Ng YT, Maganti R (2013) Status epilepticus in childhood. Journal of Paediatrics and Child Health 49 (6): 432 - 437. doi: 10.1111/j.1440-1754.2012.02559.x. 
2. Nair PP, Kalita J, Misra UK (2011) Status epilepticus: Why, what, and how. Journal of Postgraduate Medicine 57 (3): 242 252. doi: 10.4103/0022-3859.81807.

3. Tekgul H, Gauvreau K, Soul J et al. (2006) The current etiologic profile and neurodevelopmental outcome of seizures interm newborn infants. Pediatrics 117 (4): 1270 - 1280. doi: 10.1542/peds.2005-1178.

4. Sarhan AA, Ayouty MM, Elsharkawy AA, Elmagid DSA (2015) Neurodevelopmental and neurobehavioral aspects of childhood epilepsy. Benha Medical Journal 32 (1): 13 - 19. doi: 10.4103/1110-208X.170553.

5. Saz EU, Karapinar B, Ozcetin M et al. (2011) Convulsive status epilepticus in children: Etiology, treatment protocol and outcome. Seizure 8 (2): 115 - 118. doi: 10.1016/j.seizure.2010. 10.034 .

6. Hussain N, Appleton R, Thorburn K (2007) Aetiology, course and outcome of children admitted to paediatric intensive care with convulsive status epilepticus: A retrospective 5-year review. Seizure 16 (4): 305 - 312. doi: 10.1016/j.seizure.2007.01. 007.

7. Sandarangani M, Seaton C, Scott JAG et al. (2008) Incidence and outcome of convulsive status epilepticus in Kenyan children: a cohort study. The Lancet Neurology 7 (2): 145 - 150 doi: 10.1016/S1474-4422(07)70331-9.

8. Ayala A, Munoz MF, Arguelles S (2014) Lipid peroxidation: Production, metabolism, and signaling mechanisms of malondialdehyde and 4-hydroxy-2-nonenal. Oxidative Medicine and Cellular Longevity. doi: 10.1155/2014/360438.

9. Maestra SL, Kisby GE, Micale RT et al. (2011) Cigarette smoke induces DNA damage and alters base-excision repair and tau levels in the brain of neonatal mice. Toxicological Sciences 123 (2): 471 - 479. doi: 10.1093/toxsci/kfr187.

10. Rahardjani KB (2010) Hubungan antara malondialdehyde (MDA) dengan hasil luaran sepsis neonatorum. Sari Pediatri 12 (2): 82 - 87. doi: 10.14238/sp12.2.2010.82-7.

11. Li F, Yang Z, Lu Y et al. (2010) Malondialdehyde suppresses cerebral function by breaking homeostasis between excitation and inhibition. PLoS ONE 5 (12): e15325. doi: 10.1371/journal.pone.0015325.

12. Pepys MB, Hirschfield GM (2003) C-reactive protein: A critical update. The Journal of Clinical Investigation 111 (12): 1805 1812. doi: 10.1172/JCI18921.

13. Holtman L, van Vliet EA, Aronica E et al. (2013) Blood plasma inflammation markers during epileptogenesis in post-status epilepticus rat model for temporal lobe epilepsy. Epilepsia 54 (4): 589 - 595. doi: 10.1111/epi.12112.

14. Sattler JM (2001) Assessment of children: Cognitive applications. 4th ed. California, Jerome M, Sattler, Publisher, Inc.

15. Bayley N (2006) Bayley scales of infant and toddler development. San Antonio, USA: Psych Corp.
16. Bedford H, Suzanne W, Jane A (2013) Policy research unit in the health of children, young people and families. http://www.ucl.ac.uk/. Accessed date: December 2017.

17. Sleven H, Gibbs JE, Heales S et al. (2006) Depletion of reduced glutathione precedes inactivation of mitochondrial enzymes following limbic status epilepticus in the rat hippocampus. Neurochemistry International 48 (2): 75 - 82. doi: 10.1016/j.neuint.2005.10.002

18. Jarrett SG, Milder JB, Liang LP, Patel M (2008) The ketogenic diet increases mitochondrial glutathione levels. Journal of Neurochemistry 106 (3): 1044 - 1051. doi: 10.1111/j.14714159.2008.05460.x.

19. Tejada S, Sureda A, Roca C et al. (2007) Antioxidant response and oxidative damage in brain cortex after high dose of pilocarpine. Brain Research Bulletin 71 (4): 372 - 375. doi: 10.1016/j.brainresbull.2006.10.005.

20. Tsai HL, Chang CN, Chang SJ (2010) The effects of pilocarpine-induced status epilepticus on oxidative stress/damage in developing animals. Brain and Development 32 (1): 25 - 31. doi: 10.1016/j.braindev.2009.02.013.

21. Freitas RM, Vasconcelos SM, Souza FC et al. (2005) Oxidative stress in the hippocampus after pilocarpine-induced status epilepticus in Wistar rats. Federation of European Biochemical Societies Journal 272 (6): 1307 - 1312. doi: 10.1111/j.17424658.2004.04537.x.

22. Nobre Junior HV, de Franca Fonteles MM, de Freitas RM (2009) Acute seizure activity promotes lipid peroxidation, increased nitrite levels and adaptive pathways against oxidative stress in frontal cortex and striatum. Oxidative Medicine and Cellular Longevity 2 (3): 130 - 137. doi: 0.4161/oxim.2.3.8488.

23. Muzayyanah NL, Hapsara S, Wibowo T (2013) Kejang berulang dan status epileptikus pada ensefalitis sebagai faktor resiko epilepsi pascaensefalitis. Sari Pediatri 15 (3): 150 - 155. doi: 10.14238/sp15.3.2013.150-5.

24. Kovac S, Domijan AM, Walker MC, Abramov AY (2014) Seizure activity results in calcium- and mitochondria-independent ROS production via NADPH and xanthine oxidase activation. Cell Death and Disease 5: e1442. doi: 10.1038/cddis.2014.390.

25. Frantseva MV, Perez Velazquez JL, Tsoraklidis G et al. (2000) Oxidative stress is involved in seizure-induced neurodegeneration in the kindling model of epilepsy. Neuroscience 97 (3): 431 - 435. doi: 10.1016/S0306-4522(00)00041-5.

26. Kovacs R, Schuchmann S, Gabriel S et al. (2002) Free radicalmediated cell damage after experimental status epilepticus in hippocampal slice cultures. Journal of Neurophysiology 88 (6): 2909 - 2918. doi: 10.1152/jn.00149.2002.

27. Bedard K, Krause KH (2007) The NOX family of ROS-generating NADPH oxidases: physiology and pathophysiology. Physiological Reviews 87 (1): 245-313. doi: 10.1152/physrev. 00044.2005. 
28. Tekgul H, Gauvreau K, Soul J et al. (2006) The Current etiologic profile and neurodevelopmental outcome of seizures in term newborn infants. Pediatrics 117 (4): 1270 - 1280. doi: 10.1542/peds.2005-1178.

29. Vezzani A, Aronica E, Mazarati A, Pittman QJ (2013) Epilepsy and brain inflammation. Experimental Neurology 244: 11 - 21. doi: 10.1016/j.expneurol.2011.09.033.

30. Ishikawa N, Kobayashi Y, Fujii Y, Kobayashi M (2015) Increased interleukin-6 and high-sensitivity C-reactive protein levels in pediatric epilepsy patients with frequent, refractory generalized motor seizures. Seizure 25: 136 - 140. doi: 10.1016/j.seizure.2014.10.007.

31. Sutter R, Marsch S, Fuhr P, Ruegg S (2013) Mortality and recovery from refractory status epilepticus in the intensive care unit: A 7-year observational study. Epilepsia 54 (3): 502 - 511. doi: 10.1111/epi.12064.

32. Maegaki Y, Kurozawa Y, Tamasaki A et al. (2015) Early predictors of status epilepticus-associated mortality and morbidity in children. Brain and Development 37 (5): 478 - 486. doi: 10.1016/j.braindev.2014.08.004. 